\title{
Teachers' Strategies for Managing Adolescent Students with Maladaptive Behaviours in Senior High Schools in Offinso Municipality
}

\author{
Samuel Dontoh*, Med. \\ Offinso College of Education, Offinso-Ashanti. Ghana W/A
}

\begin{abstract}
Maladaptive behavior is arguably the most common disruptive behaviour among adolescents and in order to transform these students into productive members in the society, the need for quality education cannot be overrated. It is in this regard that this study seeks to examine the strategies that teachers use to manage maladaptive behaviours in Offinso Municipality. A quantitative approach and an explanatory research design was adopted to ensure that the right data is collected and the appropriate analytical techniques are used. Further, Krejcie and Morgan (1970) and stratified random sampling was used to select a total of 171 teachers from the three schools with the aid of questionnaire as the research instrument. All ethical issues were strictly adhered to ensure full corporation with the study. SPSS version 22 was used to code and capture the data collected. A combination of descriptive analysis and sequential linear regression was used to analyze the data. The results showed that the students of the three schools in the Offinso Municipality exhibit maladaptive behaviour and the teachers have adapted strategies that significantly manages the maladaptive behaviours. The factors influencing maladaptive behaviour in the adolescents includes parental, environmental and the school. For resource allocation and policy implications, management should first consider committing resources to enhancing the teacher's strategy before considering the three category of factors influencing the maladaptive behaviour in the adolescent students. Further, management should engage the parents, the community leaders and government to develop strategies in mitigating maladaptive behaviour in adolescent students. The need for counselling service centres cannot be overrated besides orientation practices.
\end{abstract}

Keywords: Maladaptive behaviour, Misbehavior, Student

DOI: $10.7176 / \mathrm{JEP} / 11-10-07$

Publication date: April $30^{\text {th }} 2020$

\section{Background to the Study}

The senior high school level marks a very delicate stage in the life of adolescent students, it is the stage at which adolescent students are expected to make a quantum change in their life (Fawcett, 2018; Elegbe,2018). At this stage, students acquire the knowledge, skills, experience and discipline that will define their destiny and set them on the path from what they used to be to what they intend to become Elegbe(2018). To further underscore the delicate nature of this stage in an adolescent's life, Elegbe(2018) made reference to child psychologist (Chorpita, 2018; Bauer, Sullivan, Szczepaniak, Ofner and Carroll, 2018; Hupp, 2019) who asserts that adolescent students at the high school level are normally within the ages of eleven and eighteen. An age range in psychology refer to as the period of storm and stress, a period where many changes occur in the life of such students at a very rapid rate. If these students are not guided with an effective strategy, Chorpita(2018) argued that they almost certainly lead to maladaptive behaviors and other forms of misbehaviours.

Chorpita(2018) emphasized that such maladaptive behaviours are considered abnormal as they fall outside socially defined norms. Also, from a statistically point of view, such behaviours fall outside the normal distributive curve for definite normality test (Bauer et al., 2018). Similarly, Hupp(2019) explained that a normal person is one who is ready or willing to demonstrate decent and decorous conduct, respect for authority, high sense of responsibility, love for orderliness, eagerness to discharge duties with promptitude and efficiency. Therefore, the failure or inability of an individual to demonstrate these traits means that maladaptive behaviour have occurred Hupp(2019) noted. In contrast to Hupp (2019) assertion, Shayota and Elsea (2019) argued that maladaptive behaviour may be very difficult to define due to standards and cultural differences. Shayota and Elsea (2019) explained that societal norms are based on cultural practices and perceptions hence what is accepted in one society may not be accepted in another though most societies overlap in their norms and believes.

Therefore, in Shayota and Elsea (2019) argument, maladaptive behaviour should be regarded as a shift from age long appropriate behaviour which significantly affects individual growth and societal development. Based on the aforementioned argument, it suffices to conclude that maladaptive behaviour can be regard as any behaviour that contradicts generally accepted pattern of behaviour for the age and environment of an individual especially if it adversely affects the individual himself and the people around him. Such maladaptive behaviours are very prominent in adolescents as defined by (Elegbe, 2018). It is at this stage that the students research the senior high school level and is sandwiched between home environment and school environment. These the home and school 
environment have different effect on the students' life and increases the stress on the student. At home, these adolescents are segregated from adult society and such segregation serves as an important contribution to antisocial behaviour by the students. On the contrary, at school they are subjected to standardized rules and regulation and encouraged to socialize and work together as a team (Elegbe, 2018).

Exposure to such conflicting environments creates the necessary conditions for maladaptive behaviour to thrive in adolescent students (Elegbe, 2018). By the same token, Torres and Giddie (2019) for his part observed that it is at this stage that students are eager to learn new experiences, to find new relationships, to examine resources of inner strength and fathom the strength of inner ability. Thus, the inability of the students to fulfill these natural demands results in maladaptive behaviour. The problem is that adolescent students with maladaptive behaviour have no regard for the moral and ethical rules of the society or the rights of others, they tend to manipulating people and situation for their own benefits (Torres and Giddie,2019). Evidence of the severity and prominence of maladaptive behaviour in senior high schools can be seen in the numerous research (Tordzro and Ofori, 2018; Peters-Burton and Johnson, 2018; Rivizzigno, Brendgen, Vitaro, Dionne and Boivin, 2018; Steele, 2018; Ndimande and Neville, 2018) done on the topic in many countries. Most of these research sort to examine the causality between maladaptive behaviours and academic performance at various levels of the educational ladder.

Although these research findings acquiesce to the advanced learner's dictionary definition of maladaptive behaviour as a way of behaving, manners, treatment shown towards others. These aforementioned researchers agree that maladaptive behaviour is a socially defined problem, a source of concern or as undesirable by the norms of conventional society and the institutions of adult authority and its occurrence usually elicits some kinds of social control response. Research findings of Tordzro and Ofori(2018) revealed that most societies particularly in Africa perceive maladaptive behaviours as a violation of a formal or informal rule including serious criminal acts or flagrant disregard for conventional standards of approved behaviour, as well as more private and momentary oppositional and hurtful acts. Peters-Burton and Johnson(2018) on the other hand found that most students with maladaptive behaviour quit or dropout of school due to severe lack of motivation or unfavorable social climate.

\section{Specific Research Objectives}

Specifically, the research seeks to examine the

1. The maladaptive behaviours that teachers encounter

2. The factors influencing maladaptive behaviour in the students

\section{Research Questions}

1. What are the maladaptive behaviours that teachers encounter?

2. What the factors influencing maladaptive behaviour in the students?

\section{Research Hypothesis}

1. There is no significant relationship between strategies adopted, factors influencing maladaptive behaviour and teachers encounter of maladaptive behaviour

\section{Significance of the Study}

The issue of maladaptive behaviour among adolescents is becoming alarming. Evidence from research findings have shown that is adversely affect academic performance of students. As such requires urgent attention. Teacher bare the lion share of the responsibility of impacting academic knowledge to adolescent students, to achieve this they need the full corporation of the students to follow the learning process. Maladaptive behaviour have shown to impede the ability of students to follow rules and regulation of schools and often times have resulted in violence, dropout and other unpleasant situations. Teachers have adopted and implemented different strategies in their effort to management students with maladaptive behaviour but with little success particularly in Ghana. Therefore, the findings of this research will serve as a source of information for stakeholders in the educational sector on how to manage maladaptive behaviour in students. Also, it will increase the alarm on the need for government to commit more resources into training and equipping teachers with the right tools and resources for them to better detect and management students with maladaptive behaviour.

\section{Theoretical Framework}

\section{Rational Emotive Behavior Theory}

Rational emotive behavior theory first began as rational emotive behavior therapy (REBT) introduced by Albert Ellis in the 1950s. It's an approach that helps to identify irrational beliefs and negative thought patterns that may lead to emotional or behavioral issues. REBT is grounded in the idea that people generally want to do well in lifespecially to achieve their goals and find happiness. But sometimes, irrational thoughts and feelings get in the 
way. These beliefs influence how a person perceive circumstances and events usually in a bad way. Albert Ellis argued that though people exhibit both rational and irrational behaviour, irrational thinking occurs in early illogical learning as a result of continuous emotional disturbance such as anxiety, depression, hatred, guilt among others.

According to the theory, though some illogical thinking in people can attributed to biological limitations, most of them are shaped through socialization processes that are done through parents, teachers, peer groups, mass media and society. The extent or severity of impact of these social features also depends on the personality of the individual in terms of beliefs, constructs or attitude. Ellis explained that rational or irrational beliefs of an individual can be explained in four basic principles known as the A-B-C-D principles. The benefits of these principles in Ellis's opinion is that it enables a proper understanding of the causality between thoughts and emotions. In this regard, Ellis argued by focusing on the philosophic reconstruction of the life style of a person, therapist can devices techniques to make people with maladaptive behaviours to get better and feel better about themselves.

Based on this assumptions, Ellis introduced the reconstruction into the principle to become A-B-C-D -E that is The Activating Factor (A), Belief or Self thought (B), Consequences of self-thought (C), Disputation (D) and Re-education (E). Bernard and Dryden (2018) used these principle in his research work on maladaptive behaviour in adolescents and observed that has a significant effect in reshaping the life of adolescents with maladaptive behaviours. Bernard and Dryden (2018) argued that the life threatening nature of maladaptive behaviour means that an individual can be thrown off balance for life by applying the five principles, a lot of irrational thinking of the adolescents were restructured. In a similar experiment, Wood, Barker, Turner and Sheffield (2018) observed that was able to control the irrational thinking of adolescent students with maladaptive behaviours using on the ABC part of the principle.

Based on the success of the results, Wood et al. (2018) explained that the A which is the Activating Factor is the maladaptive behaviour situation of the person, B which is the Belief refers to the situation where by the adjusted person begins to blame himself with different irrational thinking such as: "I am finished", "everybody is running away from me", "nobody wants to interact with me". But at the $\mathrm{C}$, these irrational thoughts result in isolation, self-denial, hatred for life

\section{Bf Skinner: Operant Conditioning Theory (1953)}

This learning theory states that people learn by continually looking for ways to achieve more positive reinforcement in terms of rewards and avoid negative reinforcement in terms of punishment (Skinner, 1953). Reinforcement is defined as a stimulus or event that affects the likelihood that an immediately preceding behavior will be repeated. Besides reinforcement, punishment produces avoidance behavior, which appears to weaken learning a particular behavior but not curtail it. It operates under the assumption that if behavior can be learned, it can also be unlearned. Skinner (1953) has been associated with operant conditioning. He believes that behaviors are influenced by a history of rewards and punishments. According to Skinner, once actions have pleasant effects, then there is the likelihood that such actions will be repeated in future. This suggests that any behavior, in a particular context that is reinforced (rewarded) in some way will tend to be repeated in that context. However, if one's actions have unpleasant effects (punishment), then one is less likely to repeat them in the future. Accordingly, behavior is the function of its consequences (Funder, 2010).In 1974, Skinner introduced the concept of shaping behavior by selectively reinforcing desired pieces of behavior. His experiment showed how encouraging feedback functioned by setting a hungry rodent in his skinner box. The case contained a lever as an afterthought and as the rodent moved about the box it would inadvertently thump the lever. Whenever it did such a food particle would drop into the compartment beside the lever. The rodent immediately figured out how to go straight to the lever after a couple of times of being placed in the crate. The results of receiving nourishment in the event that they pressed the lever guaranteed that they would repeat the action once more. This results proved that positive reinforcement fortifies a conduct by giving a consequence an individual finds remunerating.

This theory was found relevant to these study because, if for instance, teachers reward good behavior of not fighting and not bullying with words of praise or a gift, the students will more likely repeat the good behavior in future, thus strengthening it. The teachers should also note that the withdrawal of an unpleasant reinforcement or negative reinforcement can also strengthen conduct. For example, if a student misbehaves by bullying, fighting or hazing, he or she is denied a chance to go out on a sports trip or play with others. Skinner (1953), demonstrated how negative reinforcement worked by putting a rodent in his skinner box and then subjecting it to an unpleasant electric current which caused it some discomfort. The consequence of escaping the electric current prompted them to repeat the action once more. In fact, Skinner even trained the rodents to avoid the electric current by switching on a light just before the electric current came on. The rodents soon mastered to press the lever when the light was switched on because they knew that would stop the electric current being switched on.

Punishment as far as this theory is concerned is defined as the opposite of reinforcement since it is designed to weaken or get rid of a behavior practice rather than increase it. It is an aversive event that reduces the conduct 
it follows. Like reinforcement, punishment can work either directly applying an unpleasant stimulus like a shock after a response or by removing a possible remunerating event, for example by denying a student a chance to play and make him sit on the sideline for using abusive language. This makes it hard to make a difference between punishment and negative remuneration.There are a number of issues associated with punishment: punished character is not forgotten but it is only prevented and can recur when punishment is removed. The teachers should take note that punishment at times results into increased violence as a way of coping with problems. It might create phobia that can generalize to unpleasant characteristics. Punishment not always directs towards desired conduct because reinforcement tells one what to do but punishment only tells one what to avoid. This theory was chosen because it was in line with behavior modification techniques under investigation.

\section{Social Learning Theory (Albert Bandura, 1977)}

Social learning theory is propounded by Albert Bandura. This theory focus on social interaction of an individual. This theory also addresses how the behaviour of an individual influences the behaviour of another in a group process of students. Achemu (2008) believed that social learning theory explain how people learn behaviour. People learn by observing other behaviours. The good behaviour brings out desired outcome in behaviour modification social learning theory suggests that behaviour is influenced by these environmental factors or stimuli. Albert Bandure (1977) believed in Achienu's work and also in Anagbos work that this theory incorporates aspects of behavioural learning which assumes that peoples' environment (Surroundings) contribute highly to cause their behaviour. Hence, cognitive learning presumes that psychological factor are very, very important in influencing how an individual behaves.

Ngwoke (1995) opined that learning is influenced by individual differences in perception. It is often said that the colour of any object of perception will depend to an extent on the colour of the perceiver's eye glass. It is also applicable to learning because the laws that govern perception to some extent also govern learning. This explains why we may find two individuals who are attending to the same learning episode but who are learning quite different things. Biogenic and Socio-cultural characteristics peculiar to every individual learner act as sieve and organizer for presented experiences. Anagboso (2009) agreed that social learning theory views a learner as a member of social group, it is expected to give regard to disapproval or the generalized reinforces of the social group. Social learning theory also outline four requirements for people to learn and modify behaviour.It includes attention, retention remembering what one observed or heard reproduction Liability to reproduce the behaviour that is good in home and also in the classroom. Teachers should motivate good behaviour so that student will adopt the behaviour both at home, in school and in the larger society.

\section{Social Theory of Adolescence}

Erikson's theory has the core concept as the acquisition of an ego-identity, and the identity crisis an essential characteristic of adolescence. Although a person's identity is established in ways that differ from culture to culture, the accomplishment of this developmental task has a common element in all cultures. In order to acquire a strong and healthy ego-identity, Erickson was cited in Muss that the child must receive consistent and meaningful recognition of his achievements and accomplishments (Muss, 1975). Erickson (1963) sees adolescence purely from the social perspective. According to this theory, the adolescent finds it extremely difficult to identify himself and the environment. Identity formation is therefore seen as a source of tension. There is the need for the adolescent to understand himself in terms of what he can do and what he cannot do; whether he is measuring up to expectation or not.

If the adolescent is not measuring up to expectation, the crisis arises. The sociological theory sees the adolescent as performing a specific or transitory role. Specific roles include his relationship with his family, peer groups, the authority, and his relationship as an individual within the society, where the relationship between the adolescent and the said group is not cordial problem arises. Erikson describes adolescence as the period during which the individual must establish a sense of personal identity and avoid the dangers of role diffusion and identity confusion (Erikson, 1950). This implies that there is the need for the individual to make an assessment of his or her assets and liabilities and how they want to use them. Adolescents must be able to answer questions for themselves about where they came from, who they are, and what they will become. Identity, or a sense of sameness and continuity, must be searched for (King, 2004).

In our understanding of identity, it is not given to the individual by society, nor does it appear as a maturational phenomenon; it must be acquired through sustained individual efforts. Unwillingness to work on one's own identity formation carries with it the danger of role diffusion, which may result in alienation and a lasting sense of isolation and confusion. The virtue to be developed is fidelity. Adhering to one's values contributes to a stable identity (Muuss, 1975). The positive outcome of the identity crisis depends on the young person's willingness to accept his past and establish continuity with their previous experiences. To know their identity, adolescent must find an answer to the question: "Who Am I?" Other questions that must be able to answered include: "Where am I going?" "Who am I to become?" There must be a commitment to a system of 
values - religious beliefs, vocational goals, a philosophy of life, and an acceptance of one's sexuality.

Only through the achievement of these aspects of ego-identity can it be possible for the adolescent to move into "adult maturity," achieve intimacy of sexual and affection love, establish deep friendships, and achieve personal self-abandon without fear of loss of ego-identity (Muuss, 1975). Erickson believes that human development adheres to the principle of epigenesist which means that everything emerges from basic ground plan in parts, with each part experiencing a period of ascendancy, finally forming an integrated whole. He outlines eight stages of development, each stage being conflicting and having the possibility and if they resolve these conflicts, a positive self -concept is formed. But if the conflict persists or is unresolved, then a negative or dystonic element is incorporated into a person's identity, leading to a negative self -concept and psychological problems.

However, he states that both syntonic (positive) and dystonic are necessary for there to be satisfactory personal adaptation. Identity issues are never resolved and may be affected by role changes and major life events, depending on changing needs and circumstances. Optimal identity formation should include a commitment to roles, values, and sexual orientation that reflect an individual's particular abilities and needs. The inability of adolescents to find out their identity can lead to some social and academic challenges in their schools and lives. The relevance of this theory to the current study lies in the fact that identity formation among young people has an influence on the experiences they have or encounter in school. The influence can be seen in how they interpret the events surrounding their lives.

\section{Behavioral Theory of Adolescence}

Contrary to all the behavioral theories of adolescence, the one propounded by Bandura in 1964 is the most comprehensive. The theory states that the adolescent period is not a period of turmoil and stress. According to the theory, teenagers who come from stable, loving families have a relatively easy time during adolescence. By the time they reach puberty, Bandura insists, such teenagers have been so well socialized, that is, encouraged and rewarded so often for conforming to and displaying desirable behaviour that even sex does not present much of a problem (Bandura, 1964). While normal teenagers may experience some anxiety about sex and wish they had more reliable information, most identify with their parent's standards of conduct. The theory explained that those adolescents, who do experience turmoil during adolescence, are poorly socialized. An aggressive young troublemaker is not simply suffering normal pains but instead is a victim of family learning habits.

His parents have not provided him with the proper training. He is likely to come from unstable and conflictridden home, home in which fights and arguments were lamentably common occurrences. In relating this theory to the current study, it can be realized that the kind of home environment that a student comes from can influence the kind of challenges that he or she will have in school. Thus, if the person was poorly socialized, he is likely to experience a lot of social challenges especially as he deals with his peers and teachers within the school. Such a person might have difficulty making friends in school (Bandura, 1964). According to Bandura, what marks adolescence are the social and cultural pressures, attitudes and expectations that influence adolescents. An adolescent has a range of behaviors that arise from what he or she learns within and from particular social and physical environments. Thus, the focus is on the external rather than the internal influences on adolescents' behavior.

In its summary, Bandura argued that most human behaviour is learned through example, either intentionally or accidentally. Thus, individuals learn by observing other people and modeling their behaviours after the models. It is because of this that the environment in which an individual is exposed to have a bearing on their experiences in life especially school. The socialization of the individual is therefore important and influential in the challenges he/she experiences. The implication of the study requires that teachers and parents to concentrate on positively reinforcing an adolescent's appropriate behavior and where possible ignoring minor misbehavior. This is to shape an adolescent's behavior in the direction the parent or teacher desires. The teacher or parent has to be vigilant and observe in order to note appropriate behavior so as to reward or reinforce that behavior. The teacher or parent must be clear as to what target behaviors they expect the adolescent to achieve and ensure that the adolescent is also clear as to what is expected. This theory therefore had relevance to the current study.

\section{Definition of Concepts}

This section review literature relating to the key tenants of the issues relating to adolescents, maladaptive behaviour, teaching and learning process as well as strategies recommended by expects and those adopted by teachers to manage maladaptive behaviours during the teaching and learning process. The concept of maladaptive behaviour be best understood by first examining the student misbehavior (Cain\& Pincus, 2016). Such misbehavior in Cain and Pincus (2016) opinion constitutes action such as disruptive talking, chronic avoidance of work, clowning, interfering with teaching activities, harassing classmates, verbal insults, rudeness to teacher, defiance and hostility. Irrespective of the severity and frequency of it, Cain and Pincus (2016) argue that teachers usually reported that these disturbing behaviors in the classroom are intolerable. Such misbehavior 
does not only retard the smoothness and effectiveness of teaching and learning process; it alsoimpedes the learning of the student exhibiting such behaviour as well as the rest of the class.

\section{Conceptual Framework}

Managing students to behave well during teaching and learning is very important (Junek, 2018). To achieve this, there is the need to devices strategies to adjust and direct the behaviour of students particularly when dealing with adolescents with maladaptive behaviour condition (Junek, 2018). Good adjustment in behavior can only be measured by looking at how well students relate and interact with others during teaching and learning (Cadenhead et al., 2019). Developing behavior modification techniques as a strategy for handling students' maladaptive behavior may have a major impact on the how the students behave in the class room and at other social interactions with their fellow students Cadenhead et al. (2019). Similarly, when behavior modification techniques are offered to the learners who are maladaptive, there is a tendency for the maladaptive behavior to reduce or stop completely since they will only imitate behavior that is appropriate. The gender of students is likely to play a role on the maladaptive behavior portrayed during learning and interactions with other students.

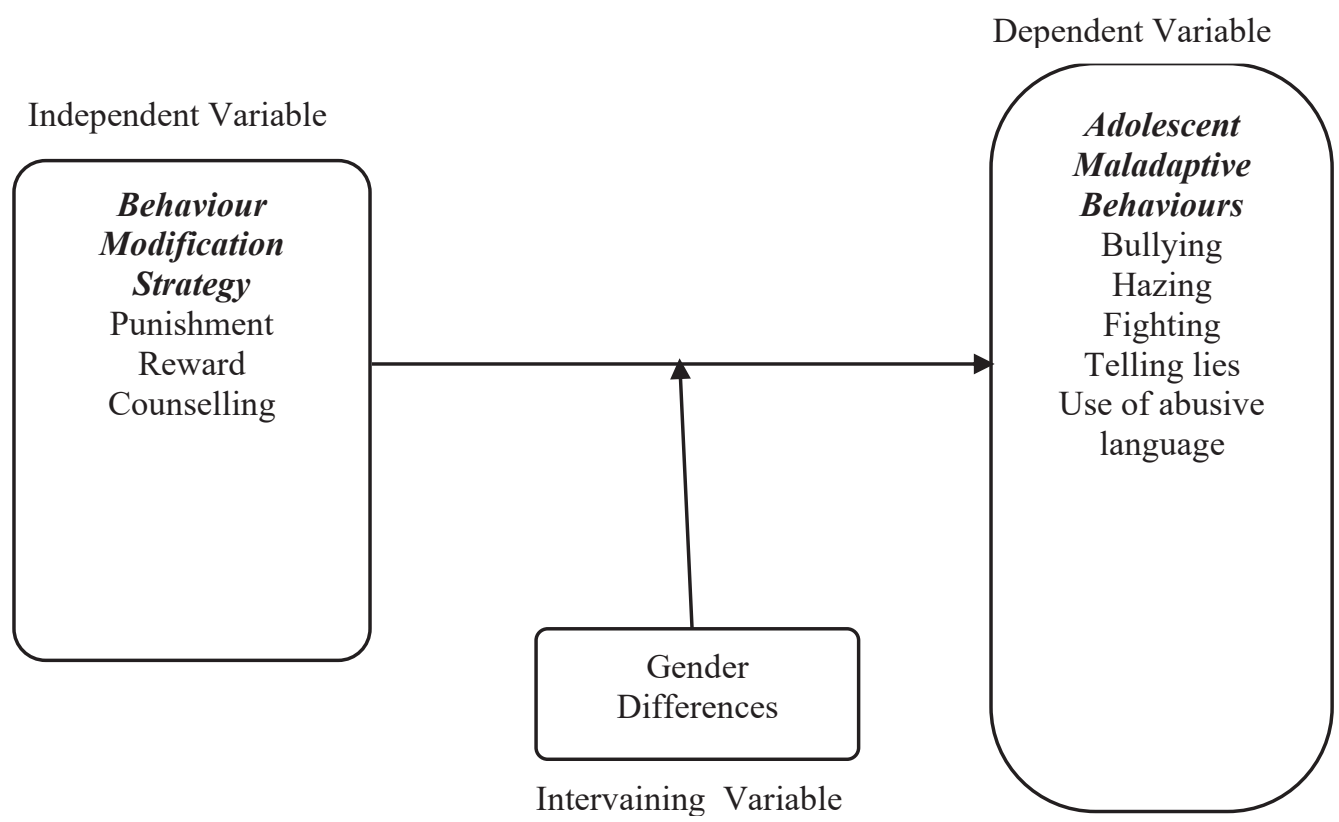

Figure 1: Conceptual Framework. Source: Authors Construct, 2020

\section{Empirical Review}

A study done in Spain on bullying among secondary school students by Yubero and Navarro (2006)discovered that differences between genders were attributed to boys' impulsive character which rendered them more physically aggressive. Yubero and Navarro used as quantitative research approach, a descriptive research design and a questionnaire to collect data on 242students. Krejcie and Morgan (1970) was used to derive the sample size of 242 from a population of 653 students. The authors use SPSS and corsstabulation analysis technique. Kariuki, Aloka, Gatumu and Gitonga, (2015) adopted Yubero and Navarro (2006) research method and found that boys tend to engage in a wider range of bullying behavior extending from direct physical aggression, to name-calling and threats. However, Kariuki et al. (2015) observed that when behavior modification techniques were applied to handle such students, there was a reduction of maladaptive behaviors of the students irrespective of their gender.

Kwaja and Mormah (2011) assessed managing adolescents' maladaptive behaviour in Nigerian Secondary Schools. The purpose of the study was to ascertain the maladaptive behaviour of secondary school students and ways of managing it. Four research questions were posed for the study. The researchers used descriptive survey design in the study. The study sample total 600 respondents including teacher and students of different genders. SPSS version 20 was used to perform descriptive analysis on the data collected. The result revealed that the use of counselling curriculum in schools, reinforcement, and counselling adolescents in moral values are the most effective strategies for managing maladaptive behaviour.

In a study carried out by Ali, Dada, Isiaka and Salmon (2014) to examine the prominent constitute maladaptive behaviour among secondary school students in Lagos State. Four research questions and two null hypotheses guided the study. The researcher used descriptive survey design in the study. Krejcie and Morgan (1970) was used to derive a sample size of 201 from a population of 423 adolescent students in senior secondary 
school. Mean, standard deviation and t-test statistical tools were used in the analysis of data gathered for the study. The results revealed that what constitute maladaptive behaviour among secondary school students include; disobedience to teachers and school's rules and regulations stealing other student's properties, staying in hostel during lesson among others.

In a similar study, Kambuga, Manyengo and Mbalamula (2018) adapted Ali et al. (2014) research method by increase the sample size to 260 from a population of 830 students. Though Kambuga et al. (2018) maintained the quantitative approach, he rather used a quasi-experimental research design and a structural equation model to design a model that established the causality between maladaptive behaviour and strategies to manage it. SmartPLS 3 was used to perform a partial least square regression analysis on the model. The results revealed that enforcement of school rules and regulations, guidance and counselling services, the use of incentives and enforcement of punishment were the most effective strategies in dealing with disobedience to teachers and school's rules and regulations stealing other student's properties, staying in hostel during lesson.

Ugwu(2017) assessed the causes of adolescents' maladaptive behaviour in secondary schools of Ebonyi State. Three research questions and one null hypothesis guided the study. The research design was survey and sample size of 361 was derived from a population of 6000 secondary school students in Ebonyi State. The sample was randomly selected through a multi-stage sampling procedure from four selected units. The instrument used for data collection was researcher designed questionnaire. Statistical instruments used for data analysis were independent t-test and analysis of variance (ANOVA). The results of the study revealed that the causes of adolescents' maladaptive behaviour include; family background, socio-economic status of parents, the school, peer influence and influence of mass media. The results also showed that there was no significant difference between male and female students on the causes of maladaptive behaviour.

Muteki, Morgado, Reid, Wang and Miller (2013)carried out a study on teachers' perceptions of pupils' maladjustment problems from a psycho-social perspective. The study explored teachers' perceptions of maladjustment problems manifested by pupils in South Africa primary schools using the psycho-social bens to view and interpret the phenomena. The study involved 32 primary school educators participated in the study. The sample of educators was randomly selected from eight primary schools in the central Johannesburg district. The survey design adopted combined both qualitative and quantitative approaches. Data were collected through questionnaires and interviews. The study found that teachers who were not adequately trained to deal with maladjusted pupils did not endeavour to implement any interventions to alleviate them.

It also revealed that not all maladjusted pupils cause disciplinary problems for teachers as some of the pupils who are unsocial, withdrawn, unhappy, depressed, fearful and nervous do attract very little attention to themselves. In examining the causes of pupil maladjustments the study found that these can be traced to some unfulfilled or thwarted psychosocial needs. Therefore, the implementation of intervention strategies is likely to be more successful with adequate training and support for school personnel especially teachers.

In a qualitative study to examine the lead causes of maladaptive behaviour in adolescent in senior high school level in Accra Ghana, Glozah and Pevalin (2014) adopted a case study approach and an in focus group discussion method. A total of 50 students were randomly sampled to participate in the discussion. The results revealed that adolescents' family background characterized by frequent fighting between parents, lack of parental love and affection, divorce and different forms of deprivations including psychological and materials could lead to maladaptive behaviours. In addition, adolescents from polygamous background tend to be maladaptive than those from monogamous background. Adolescents from broken homes also exhibit maladaptive behaviour especially when both parents are separated and cannot reinforce and motivate these adolescents.

Furthermore, Glozah and Pevalin (2014) observed that evidence for the discussion points to socio-economic status of parents. Maladaptive behaviour was attributed to poverty arising from low socio-economic status of parents. Adolescents from poor homes are usually deprived of some basic needs of life. Glozah and Pevalin explained that the fact that poor parents may not be able to satisfy all their needs, the children may take to other means such as stealing and the likes to provide for themselves and satisfy their materials quests. Also, Glozah and Pevalin noted that the School bares a fair share of the problem of maladaptive behaviour. The students explained that unruly behaviour of some teachers and lack of adequate support services like overcrowded lecture halls, unequipped laboratories, libraries and hostel accommodation lead to some students exhibiting maladaptive behaviour. Furthermore, some teachers with loose manners often influence students negatively. Besides, dysfunctional school administration and hostile leadership style also caused students maladaptive behaviour.

In a similar qualitative study on indiscipline behaviour among students of Mampong Technical College in Ashanti region of Ghana, Boamah (2010) interviewed 150 students randomly selected from 5 high schools in the region. The results indicated that Peer Influence contributes significantly to adolescent's maladaptive behaviour. Boamah (2010) explained that sometimes, adolescents follow the dictates of their peers in other to create what Boamah (2010)called "peer uniformity". This means that they want to conform to the group's norms because they want to belong. However, they fail to examine it such attitudes they try to conform to are in line with 
societal value or not. This to some extent, contributed to maladaptive behaviour usually exhibited by these adolescents. Boamah (2010) also noted that the influence of mass media on adolescents behaviour and concludes that adolescents are greatly influenced by what they watch from movies and certain presentations by the mass media. Boamah (2010) observed that adolescents have greater attraction to view human sexuality films

\section{Research Design}

This study will adopt an explanatory research design approach; this is because with such an approach the researcher is able to focus on the why questions. Explanatory approach enables the study to describe and explain a phenomenon a well as the rate of changes occurring at a time (Schutt, 2018). This means that the researcher describes the maladaptive rates among adolescent students in the Offinso Municipality as well as to examine trends over time or to compare the rates found in the literature review. More so, the researcher is able to develop explanations about why the maladaptive behaviour rate is as high as it is Municipality, why some types of maladaptive behaviour are increasing or why the rate is higher in Municipalities in the country than in others.

Adopting an explanatory research design is fundamentally affected by whether the research question is descriptive or explanatory and by extension affects what information is collected (Panke, 2018). This means that before the researcher can examine the strategies teachers adopt and implement to deal with maladaptive adolescent students and its effectiveness, there is the need to first understand why (reasons) maladaptive behaviour is occurring. The significance of explanatory design in this instance is that though they may be different and inconsistent reasons for such behaviour, the explanatory approach enables the researcher to analyze the information in a way that reveals the most prominent cause of maladaptive behaviour and why from an empirical view point.

Explanatory research design enables a causal analysis and explanation (Bakla, 2018). Therefore, the researcher will be able to explain why maladaptive behaviour is high in Offinso, the nature of the effect of the teacher's strategies in dealing with maladaptive behaviour and the role of gender in adolescent maladaptive behaviour. These explanations can give further information such as whether there is a direct effect or inverse effect as well as significance of the effect (Panke, 2018). Irrespective of the complexity of the relationship, with explanatory research approach, the research is able to give a clear picture of the phenomenon.

\section{Study Area}

The study will be done in Offinso Municipality

\section{Population}

The population of this study consists of all public Senior High School teachers in the Offinso Municipality with population of 308 teachers and the three head teachers in the three public senior high school (GES, Offinso Municipality, 2018). Below is the breakdown on the respective number of teachers per school.

Table 1: Population Distribution of Respondents

\begin{tabular}{lccc}
\hline Schools & Male Teachers & Female Teachers & Total \\
\hline Dwamenakenten & 81 & 16 & 97 \\
Namong SHTS & 93 & 30 & 123 \\
St. Jerome SHS & 70 & 18 & 88 \\
Totals & 244 & 64 & 308 \\
\hline
\end{tabular}

Source: Offinso Municipality Ghana Education Service, 2020

\section{Sample and Sampling Procedure}

To be able to effectively collect required data from the three different schools in the municipality, stratified random sampling technique will be adopted. Stratified random sampling is a method of sampling that involves the division of a population into smaller sub-groups known as strata based on members' shared attributes or characteristics such as income or educational attainment (Csuros, 2018). The benefits of stratified sampling is that it highlight differences between groups in a population as opposed to simple random sampling which treats all members of a population as equal with an equal likelihood of being sampled.

This means that each of the three schools will be treated as a strata and the respective population for each stratum will be calculated based on the total sample size for the three schools. Krejcie and Morgan (1970) formula will be used to calculate the sample size for the three school.

$$
S S=\frac{X^{2} N P(1-P)}{d^{2}(N-1)+X^{2} P(1-P)}
$$

Equation 1: Formula to Derive Sample Size for the study. Source: Krejcie and Morgan (1970) Where 
$\mathrm{SS}=$ sample size of a finite population size, $\mathrm{X}=\mathrm{z}$-value or confidence level of $95 \%$ which known to be $1.96, \mathrm{~N}=$ population size (308), $\mathrm{P}=$ Population proportion (expressed as decimal) (assumed to be $0.5(50 \%)$ and $\mathrm{d}=$ Degree of accuracy (5\%), expressed as a proportion (.05); It is margin of error. The above formula is for calculating sample size of finite population.

$$
\begin{aligned}
& S=\frac{(1.96)^{2}(308)(0.5)(1-0.5)}{(0.05)^{2}(308-1)+(1.96)^{2}(0.5)(1-0.5)} \\
& =\frac{(295.8032)}{(0.0025)(307)+(3.8416)(0.25)} \\
& =\frac{295.8032)}{0.7675+0.9604} \\
& =\frac{295.8032)}{1.7279} \\
& \text { ss }=171.19 \\
& \text { ss } \approx 171
\end{aligned}
$$

\section{Equation 2: Derived Sample Size for the three Schools}

Thus, the sample size for the three selected schools is 171 teachers. This means that out of the total of 308teachers in the three schools, the researcher invited a total of 171 teachers to participate in the study. However, the specific number of teachers to be selected from each of the three school is shown in table 1. Deriving the sample size for teachers of each school is based on the formula:

$$
\begin{gathered}
\begin{array}{c}
\text { Sample } \\
\text { total number of teachers per school }
\end{array} \\
\text { total number of teacher for the three schools Combined } \\
\text { Equation 3: Sample Size for number of teachers per school }
\end{gathered}
$$

Table 2: Sample Distribution for Teachers of Each School

\begin{tabular}{lccc}
\hline Schools & Number of teachers & Procedure & sample size \\
\hline Dwamenakenten SHS School & 97 & $97 \times 171 / 308$ & 54 \\
Namong SHTS & 123 & $123 \times 171 / 308$ & 68 \\
St Jerome SHS & 88 & $88 \times 171 / 308$ & 49 \\
Total & 308 & & 171 \\
\hline
\end{tabular}

Source: Offinso Municipality Ghana Education Service, 2020

\section{Research Instrument}

Due to the large size of the sample need for this research, a questionnaire will be used as the instrument for data collection.Questionnaires can be classified as both, quantitative and qualitative method depending on the nature of questions (Taber, 2018). Specifically, answers obtained through closed-ended questions with multiple choice answer options are analyzed using quantitative methods while answers obtained to open-ended questionnaire questions are analyzed using qualitative methods and they involve discussions and critical analyses without the use of numbers and calculations (Taber, 2018).Advantages of questionnaires include increased speed of data collection, low or no cost requirements, and higher levels of objectivity compared to many alternative methods of primary data collection. However, questionnaires have certain disadvantages such as the selection of random answer choices by respondents without properly reading the question. Moreover, there is usually no possibility for respondents to express their additional thoughts about the matter due to the absence of a relevant question (Shekhar, Prince, Finelli, Demonbrun \& Waters,2019).

This research adopts questions used by Mukhaye (2018) who carried out a research on behaviour modification techniques used by teachers to change maladaptive behaviours of secondary school students in Bungoma County, Kenya. Due to its success in data collection, many other researchers Kristin (2014) used it to examine maladaptive behavior in college students and breaking student codes of conduct, Aboh, Nwankwo, Agu, Chikwendu (2014) used it in their study to examine factors influencing maladaptive behaviour among high school students in University of Science and Technology Enugu, Nigeria. The questions are closed ended questions rated on a Likert Scale that ask question with regard to maladaptive behaviour in students, strategies teachers adopt, factors influencing these behaviour and challenges encountered by teachers when dealing with maladaptive behaviours in adolescents.

However, modifications were made to the question in terms of language structure to ensure that it suits the objectives of this research. This was done to further enable the teachers get a proper understanding of the 
requirements of each question. Thus, the reliability of the data was assured.

\section{Data Collection Process}

During the data collection process, all ethical issues were strictly observed to ensure that the teacher gave their full support to the researcher. Also, the teacher were made aware of the academic nature of the data as such the need to answer as honest as possible. However, due to the busy and time-bound nature of school activities, it was not be possible forall the teachers to provide the needed information immediately thus in such instances, the researcher will negotiate with them to take the questionnaire home where they many have time to provide the data and return it on a scheduled date. Furthermore, the researcher was either available physically or via phone to explain to any teacher who did not understand any aspect of the questionnaire.

\section{Data Collection Issues}

The researcher did not encounter any serious issues during the data collection process other than some teacher forgetting to return the questionnaires on the scheduled data. In such cases the researcher returned to collect the questionnaire on a later date. Also, some teachers were not sure of management's reaction to their involvement in the study but with assurances of the heads, the teacher gave their full support.

\section{Data Processing and Analysis}

Upon retrieving all the questionnaires, they were examined and pruned for errors. SPSS version 22 was used to code and capture each response. Missing value analysis was used to perform to examine the pattern of response. The results revealed that the missing values were not sufficient to render the data invalid. For the first three research objectives, descriptive analysis was used to examine the mean responses, the measure of dispersion, the Cronbach's alpha and the ANOVA analysis to determine if there are significant variations in the response.

Furthermore, sequential regression analysis was used to examine the effectiveness of the strategies the teachers use to management maladaptive behaviour in terms of how it influences the maladaptive behaviours they encountered and how the factors influencing such behaviours also affect the relationship. This it to give a clear implication of how resources are to be allocated and policies are to be structured. To achieve this, SPSS version 22 was used to transform each subsection into a single response by using the compute function. This gave three respective variables; encountered maladaptive behaviours, factors influencing maladaptive behaviour and teachers' strategies in managing maladaptive behaviours.

Thereafter, sequential linear regression was used to examine the effect of the teacher strategies in handling maladaptive behaviour on the maladaptive behaviours encountered. Since all these three variables occur in the same environment, factors influencing maladaptive behaviour was added to the sequence to examine changes on the encountered maladaptive behaviours. The model for the regression analysis was based on the general linear equation

$\mathrm{Y}=\mathrm{a}+\mathrm{B}_{1} \mathrm{X}_{1}+\mathrm{B}_{2} \mathrm{X}_{2}+\mathrm{B}_{3} \mathrm{X}_{3}+\ldots \ldots \ldots+\mathrm{B}_{\mathrm{n}} \mathrm{X}_{\mathrm{n}}$

Equation 4: The Regression Model for the Study

Where

$\mathrm{Y}=$ is the dependent variable, $\mathrm{a}=$ Regression Constant, $\mathrm{X}=$ Unstandardized coefficient of independent variables, $\mathrm{B}=$ independent variables, $1,2,3, \ldots \ldots, \mathrm{n}=$ number of independent variables, $\mathrm{n}=$ total number of independent variables.

From the model, teacher's strategies and factors influencing maladaptive behaviour are the independent variables whilst encountered maladaptive behaviour is the dependent variable. the regression model is written as Encountered Maladaptive Behaviour $=\mathbf{a}+$ Teachers Strategies $\left(B_{1}\right)+$ Factors Influencing Maladaptive behaviour $\left(\mathbf{B}_{2}\right)$

Equation 5: Conceptual Equation for the Linear Regression Model

Table 3: Reliability Analysis

\begin{tabular}{|c|c|c|c|c|c|}
\hline \multirow[t]{2}{*}{ Construct } & \multirow{2}{*}{$\begin{array}{l}\text { Cronbach's } \\
\text { Alpha }\end{array}$} & \multirow[t]{2}{*}{ Reliability } & \multicolumn{2}{|c|}{ ANOVA } & \multirow{2}{*}{$\begin{array}{l}\text { No. of } \\
\text { Items }\end{array}$} \\
\hline & & & $\mathrm{F}$ & Sig & \\
\hline $\begin{array}{l}\text { The Maladaptive Behaviours That Teachers } \\
\text { Encounter }\end{array}$ & 0.888 & $88.8 \%$ & 13.564 & 0.00 & 16 \\
\hline $\begin{array}{l}\text { The Factors Influencing Maladaptive Behaviour in } \\
\text { the Students }\end{array}$ & 0.782 & $78.2 \%$ & 14.799 & 0.00 & 15 \\
\hline $\begin{array}{l}\text { Strategies that Teacher Use to Manage Maladaptive } \\
\text { Behaviour of Students }\end{array}$ & 0.798 & $79.8 \%$ & 22.795 & 0.00 & 12 \\
\hline
\end{tabular}

Source: Field Survey Data, 2020

The Maladaptive Behaviours That Teachers Encounter

Evidence from table 3 shows that the teachers encounter a number of maladaptive behaviours in their students. 
Among the 17 maladaptive behaviours presented to the teachers, bullying others, delinquent behaviour, anger and truancy were the prominent maladaptive behaviours the teachers encountered. Further, the teachers indicated they were not sure about bringing noisy electric devices into the classroom, obsessive compulsive behaviour and psychotic disorder. For the remaining nine maladaptive behaviours, the teacher agreed that the students exhibit such behaviours. The results in table 2 shows that the responses of the teachers to these maladaptive behaviours were $88.8 \%$ reliable and the ANOVA results further indicate there were significant variations in the responses among the teachers. This means that the responses does not linearly predict each other.

These findings are similar to Cain and Pincus (2016) noted maladaptive behaviours such as disruptive talking, chronic avoidance of work, clowning, interfering with teaching activities, harassing classmates, verbal insults, rudeness to teacher, defiance and hostility. They further observed that teachers reported all sort of behaviours that disrupt the smooth and effective teaching process. Similarly, the results affirm the work of Yubero and Navarro (2006) especially identifying bullying as a prominent maladaptive behaviour among students. The only variations are that Yubero and Navarro examined maladaptive behaviours with respect to gender and found that boys tend to engage in a wider range of bullying behavior extending from direct physical aggression, to name-calling and threats.

Similarly, research work of Ali et al (2014) showed that disobedience to teachers and school's rules and regulations stealing other student's properties, staying in hostel during lesson among others were the prominent maladaptive behaviours of students. These behaviours conforms to the results on this study are they fall under truancy, delinquency, unfriendly behaviour, bipolar disorder and psychotic disorder. Similarly, these findings conform to Muteki et al (2013) who noted that unsocial, withdrawn, unhappy, depressed, fearful and nervous do attract very little attention to themselves were very common maladaptive behaviours of students.

Table 4: Maladaptive Behaviour that Teachers Encounter

\begin{tabular}{llll}
\hline Maladaptive Behaviour & Mean & SD & N \\
\hline Bullying Others & & & 171 \\
Unfriendly Behaviour & 1.91 & 0.124 & 171 \\
Withdrawn Behaviour & 2.25 & 1.194 & 171 \\
Delinquent Behaviour & 2.83 & 1.119 & 171 \\
Avoidance & 1.15 & 0.033 & 171 \\
Anger & 2.35 & 1.171 & 171 \\
Substance Abuse & 1.27 & 0.113 & 171 \\
Bringing Noisy Electric Devices Into The & 2.94 & 0.965 & 171 \\
Classroom & 3.79 & 1.152 & \\
Learning Disabilities & 2.55 & 1.053 & 171 \\
Feeling Intimidated & 2.56 & 1.099 & 171 \\
Anxiety Disorder & 2.80 & 1.105 & 171 \\
Bipolar Disorder & 2.29 & 1.079 & 171 \\
Eating Disorder & 2.56 & 1.172 & 171 \\
Obsessive Compulsive Behaviour & 3.15 & 1.150 & 171 \\
Psychotic Disorder & 3.11 & 1.107 & 171 \\
Truancy & 1.98 & 0.975 & 171 \\
\hline
\end{tabular}

Source: Field Survey Data, 2020

\section{The Factors Influencing Maladaptive Behaviour in the Students}

It can be observed in table 4 that the teachers believed that parental attitude, poor parental control, influence of media, influence of social clubs, autocracy of school leadership, injustice in school management and autocratic leadership of teachers are the most prominent factors influencing maladaptive behaviour among the students of the three schools in the circuit. However, teachers were not sure as to whether Religion, orphan Children and Poor Academic Performance influenced maladaptive behaviour in the students. For the remaining five factors in table 4, the teachers agreed that they influenced maladaptive behaviour in the students in one way or the other. The Cronbach's Alpha value in table 2 shows that these responses of the teachers are $78.2 \%$ reliable and the ANOVA resulted also indicates significant variations in responses of the teacher. 
Similarly, Ugwu (2017) found that the causes of adolescents' maladaptive behaviour includes family background, socio-economic status of parents, the school, peer influence and influence of mass media. However, Ugwu further noted there was no significant difference between male and female students on the causes of maladaptive behaviour.Muteki et al (2013) also identified unfulfilled or thwarted psychosocial needs as a lead cause of maladaptive behaviour in adolescent student.The findings of Glozah and Pevalin (2014) on the other hand was much similar to that of this study. Glozah and Pevalin found adolescents' family background characterized by frequent fighting between parents, lack of parental love and affection, divorce and different forms of deprivations including psychological and materials could lead to maladaptive behaviours strongly influenced maladaptive behaviour.

In addition, Glozah and Pevalin noted that adolescents from polygamous background tend to be maladaptive than those from monogamous background. Similarly, adolescents from broken homes also exhibit maladaptive behaviour especially when both parents are separated and cannot reinforce and motivate these adolescents. Glozah and Pevalin noted that besides socioeconomic factors such as poverty, the School bares a fair share of the problem of maladaptive behaviour such as unruly behaviour of some teachers and lack of adequate support services. Furthermore, some teachers with loose manners often influence students negatively. Besides, dysfunctional school administration and hostile leadership style also caused students maladaptive behaviour.

Table 5: Factors Influencing Maladaptive Behaviour

\begin{tabular}{llll}
\hline Factors Influencing Maladaptive Behaviour & Mean & Std. Deviation & $\mathrm{N}$ \\
\hline Parental Attitude & 1.90 & 1.126 & 171 \\
Religion & 3.22 & 1.972 & 171 \\
Poor Parental Control & 1.24 & 0.026 & 171 \\
Polygamous Home & 2.83 & 1.142 & 171 \\
Socioeconomic Factors & 2.25 & 1.100 & 171 \\
Single Parenting & 2.01 & 1.038 & 171 \\
orphan Children & 3.04 & 1.984 & 171 \\
Poor Academic Performance & 3.28 & 1.141 & 171 \\
Poor Recreational Facilities & 2.28 & 1.013 & 171 \\
Influence of Media & 1.72 & 0.196 & 171 \\
Influence of Social Clubs & 1.26 & 0.038 & 171 \\
Social Discrimination & 2.62 & 1.102 & 171 \\
Autocracy of School Leadership & 1.11 & 0.115 & 171 \\
Injustice in School Management & 1.57 & 0.906 & 171 \\
Autocratic Leadership of Teachers & 1.98 & 0.915 & 171 \\
\hline Source: Field Survey Data, 2020 & &
\end{tabular}

Source: Field Survey Data, 2020

\section{Summary}

The results of the study are summarized into four categories in line with the research objective.

The Maladaptive Behaviours That Teachers Encounter

The teachers across the three schools in the Offinso municipality unanimously observed that bullying others, delinquent behaviour, anger and truancy were the most common maladaptive behaviours exhibit by their respective students. However, the teachers did not observe much ofmaladaptive behaviours such obsessive compulsive behaviour, psychotic disorder or the students bringing noisy electric devices into the classroom. These responses were $88.8 \%$ reliable for policy and resources allocation and they varied significantly between the teachers and across the three schools. These findings affirmed the results of Cain and Pincus (2016), Ali et al (2014) and Muteki et al (2013) and supported by the rational emotive theory, behavioural theory and BF Skinner's theory.

The Factors Influencing Maladaptive Behaviour in the Students

The teachers observed that that parental attitude, poor parental control, influence of media, influence of social clubs, autocracy of school leadership, injustice in school management and autocratic leadership of teachers were the most influential factors causing maladaptive behaviour among the students of the three schools in the circuit. However, they noted that religion, orphan children and poor academic performance did not influence maladaptive behaviour in the students. These observations were $78.2 \%$ reliable for policy consideration and resource allocation and varied significant among the teachers cross the three schools. It was further underpinned by BF Skinners theory, social learning theory and Behavioural theory. The finds were similar to that of Ugwu (2017), Muteki et al (2013) and varied slightly from the findings of Glozah and Pevalin (2014)

\section{Recommendations}

For policy implications, management of the three schools in the Offinso Municipality should commit more 
resources to improving on the current strategies that the teachers are using to manage the students maladaptive behaviours they encounter. Management should further device more effective strategies in consultation with the teachers to better handle maladaptive students. The parent teacher association and community leaders should be educated on practices the influence maladaptive behaviours in adolescents. They should be encouraged to work in consultation with the schools to identify, manage and guide students with maladaptive behaviours.

Though the teachers are doing their best professionally and privately to help deal with maladaptive behaviours, management of the school should commit more resources to further improving the professional competence of the teachers as well as improve their own management practices and school policies that fosters maladaptive behaviours in the students. Lastly, repeated request should be made to higher authorities including government to help create a guidance and counselling services sections for students to management not only maladaptive behaviours but also other factors that hinders the student's ability to grow as adolescents.

\section{Suggestions for Future Research}

Future research could focus on the socioeconomic dimensions of maladaptive behaviour and well as the effect of cultural practices. Also, there is evidence that orientation practices and guidance and counselling services have impact on maladaptive behaviours hence future research could examine the orientation practices and guidance and counselling services of the schools in Offinso Municipality and how they impact on student's behaviour. Similarly, future study could examine the impact of maladaptive behaviours on academic performance of the students.

Acknowledgment: Wilson Kwesi Nkum (PhD), Augustine Adjei (MPhil/Med.), Gertrude Dontoh, Allswell, Samuella and Jefferey.

\section{References}

Ali, A. A., Dada, I. T., Isiaka, G. A., \& Salmon, S. A. (2014). Types, causes and management of indiscipline acts among secondary school students in Shomolu Local Government Area of Lagos State. Journal of studies in social sciences, 8(2).

Bakla, A. (2018). Learner-generated materials in a flipped pronunciation class: A sequential explanatory mixedmethods study. Computers \& Education, 125, 14-38.

Bandura, A. (1977). Self-efficacy: toward a unifying theory of behavioral change. Psychological review, 84(2), 191.

Bauer, N. S., Sullivan, P. D., Szczepaniak, D., Stelzner, S. M., Pottenger, A., Ofner, S., ... \& Carroll, A. E. (2018). Attention deficit-hyperactivity disorder group visits improve parental emotional health and perceptions of child behavior. Journal of Developmental \& Behavioral Pediatrics, 39(6), 461-470.

Boamah, Y. F. (2010). Indiscipline behaviour among students of Mampong Technical College in Ashanti region of Ghana (Doctoral dissertation, University of Cape Coast).

Boyer, K. (2018). Effective Social Work Practice with Military, Veterans, and their Families.

Cadenhead, J. W., Wolf, R. L., Lebwohl, B., Lee, A. R., Zybert, P., Reilly, N. R., ... \& Green, P. H. R. (2019). Diminished quality of life among adolescents with coeliac disease using maladaptive eating behaviours to manage a gluten-free diet: a cross-sectional, mixed-methods study. Journal of Human Nutrition and Dietetics, 32(3), 311-320.

Cain, N. M., \& Pincus, A. L. (2016). Treating maladaptive interpersonal signatures.

Chorpita, B. F. (2018). Child \& Adolescent Psychotherapy: Components of Evidence-Based Treatments for Youth and their Parents. Cambridge University Press.

Csuros, M. (2018). Environmental sampling and analysis for technicians. CRC press.

Dryden, W., Dryden, W., Bernard, M. E., Bernard, M. E., Bernard, M. E., David, O., ... \& David, O. (2018). The PRACTICE model of coaching: Towards a solution-focused approach. In A Practical Guide to Rational Emotive Behavioural Coaching (Vol. 3, pp. 1-1). Chichester: Open University Press.

Elder, G. H. (2018). Children of the great depression. Routledge.

Elegbe, O. (2018). Sexual Communication: A Qualitative Study of Parents and Adolescent Girls Discussion about Sex. Journal of Health Management, 20(4), 439-452.

Fawcett, C. (2018). Understanding people: Ministry to all stages of life.

Firestone, R. W., \& Solomon, S. (2018). Separation Theory: Sheldon Solomon Interview With Robert Firestone. Journal of Humanistic Psychology, 0022167818796881.

Gagne, R. M. (1970). The learning of concepts IN Clarizio, HF, Craig, RC \& Mehrens WA (Eds.) Contemporary Issues in Educational Psychology 230-237.

Gerade, A. O. (2019). A New Order of Things: How Does a Secondary School Principal Lead a Community out of School Turnaround (Doctoral dissertation, University of Massachusetts Lowell).

Glozah, F. N., \& Pevalin, D. J. (2014). Social support, stress, health, and academic success in Ghanaian adolescents: A path analysis. Journal of Adolescence, 37(4), 451-460. 
Henseler, J. (2018). Partial least squares path modeling: Quo vadis?. Quality \& Quantity, 52(1), 1-8.

Hupp, S. (Ed.). (2019). Pseudoscience in Child and Adolescent Psychotherapy: A Skeptical Field Guide. Cambridge University Press.

Junek, W. (2018). Practical crisis management for parents and clinicians: adolescent suicidal, aggressive, elopement behaviours: intensive treatment settings. Journal of the Canadian Academy of Child and Adolescent Psychiatry, 27(3), 182.

Kambuga, Y. M., Manyengo, P. R., \& Mbalamula, Y. S. (2018). Corporal Punishment as a Strategic Reprimand used by Teachers to curb Students' Misbehaviours in Secondary Schools: Tanzanian Case. International Journal of Education and Research, 6(4).

Kariuki, N. S., Aloka, P. J., Gatumu, H. N., \& Gitonga, C. (2015). Relationship between perceptions of parental punitive discipline and involvement in delinquent behaviours among selected Kenyan secondary school students. Journal of Educational and Social Research, 5(1), 329.

Khan, G. F., Sarstedt, M., Shiau, W. L., Hair, J. F., Ringle, C. M., \& Fritze, M. P. (2019). Methodological research on partial least squares structural equation modeling (PLS-SEM) An analysis based on social network approaches. Internet Research.

Khan, G., Sarstedt, M., Shiau, W. L., Hair, J. F., Ringle, C. M., \& Fritze, M. (2019). Methodological research on partial least squares structural equation modeling (PLS-SEM): A social network analysis. Internet Research.

Khan, R. (2018). Attitudes towards 'honor'violence and killings in collectivist cultures: gender differences in Middle Eastern, North African, South Asian (MENASA) and Turkish populations. In The Routledge International Handbook of Human Aggression (pp. 216-226). Routledge.I

Kiiza, M., \& Basheka, B. C. (2018). Indigenous Management Practices in Africa.

Krejcie, R. V., \& Morgan, D. W. (1970). Determining sample size for research activities. Educational and psychological measurement, 30(3), 607-610.

Kwaja, P. E. T. E. R., \& Mormah, F. O. (2011). Managing Adolescents Maladaptive Behaviour in Nigerian Secondary Schools. Approaches in International Journal of Research Development, 3(1), 281-287

Mukhaye, L. O. A. (2018). Behaviour modification techniques used by teachers to change maladaptive behaviours of secondary school students during games in Kimilili-Bungoma County, Kenya (Doctoral dissertation, Kenyatta University).

Muteki, K., Morgado, J. E., Reid, G. L., Wang, J., Xue, G., Riley, F. W., ... \& Miller, I. J. (2013). Quantitative structure retention relationship models in an analytical quality by design framework: simultaneously accounting for compound properties, mobile-phase conditions, and stationary-phase properties. Industrial \& Engineering Chemistry Research, 52(35), 12269-12284.

Naicker, S. M., \& Naicker, S. M. (2018). Changing Consciousness', Inclusive Education in South Africa and the Developing World.

Nardi, P. M. (2018). Doing survey research: A guide to quantitative methods. Routledge.

Ndimande, B. S., \& Neville, H. A. (2018). Urban Education and Black Racial Identity in South Africa. Urban Education, 53(7), 929-956.

Nunan, J. S. R. (2018). Victims' experiences of learner challenging behaviour in primary schools in Phoenix, South Africa. South African Journal of Education, 38(1).

Ogwo, B. A. (2018). Re-visioning Technical Vocational Education and Training (TVET) for the Youth in subSaharan Africa (SSA) and the Sustainable Development Goals (SDGs): Prospects and Promises Within the Framework of the Ubuntu Paradigm. In Re-Visioning Education in Africa (pp. 155-173). Palgrave Macmillan, Cham.

Ojewola, F. O. (2017). The Relative Efficacy of Reality Therapy Procedure in Reducing Indiscipline Among InSchool Adolescents. International Journal of Vocational Education and Training Research, 2(6), 34.

Ong, C. M., Canter, C. E., Gutierrez, F. R., Sekarski, D. R., \& Goldring, D. R. (1992). Increased stiffness and persistent narrowing of the aorta after successful repair of coarctation of the aorta: relationship to left ventricular mass and blood pressure at rest and with exercise. American heart journal, 123(6), 1594-1600.

Panke, D. (2018). Research Design \& Method Selection: Making Good Choices in the Social Sciences. Sage.

Paulhus, D. L., \& Williams, K. M. (2002). The dark triad of personality: Narcissism, Machiavellianism, and psychopathy. Journal of research in personality, 36(6), 556-563.

Peters-Burton, E. E., \& Johnson, T. (2018). Cross-Case Analysis of Engineering Education Experiences in Inclusive STEM-Focused High Schools in the United States. International Journal of Education in Mathematics Science and Technology, 6(4), 320-342.

Pretorius, Y., Garaï, M. E., \& Bates, L. A. (2019). The status of African elephant Loxodonta africana populations in South Africa. Oryx, 53(4), 757-763.

Rivizzigno, A. S., Brendgen, M., Vitaro, F., Dionne, G., \& Boivin, M. (2018). Links between friends' behaviors and the emergence of leadership in childhood: A genetically informed study of twins. Social Development, 27(2), 279-292. 
Schmid, P. F. (2018). Going beyond orthodoxy in an orthodox way? Remarks to Jobst Finke's plea to extend person-centered therapy by pre-Rogerian means. Person-Centered \& Experiential Psychotherapies, 17(2), 132-138.

Schutt, R. K. (2018). Investigating the social world: The process and practice of research. Sage Publications.

Shayota, B. J., \& Elsea, S. H. (2019). Behavior and sleep disturbance in Smith-Magenis syndrome. Current opinion in psychiatry, 32(2), 73-78.

Shekhar, P., Prince, M., Finelli, C., Demonbrun, M., \& Waters, C. (2019). Integrating quantitative and qualitative research methods to examine student resistance to active learning. European Journal of Engineering Education, 44(1-2), 6-18.

Taber, K. S. (2018). The use of Cronbach's alpha when developing and reporting research instruments in science education. Research in Science Education, 48(6), 1273-1296.

Taber, K. S. (2018). The use of Cronbach's alpha when developing and reporting research instruments in science education. Research in Science Education, 48(6), 1273-1296.

Tordzro, G., \& Ofori, K. N. (2018). A Comparative Study Of Biology Practical Lessons In Selected WellEndowed And Less-Endowed Senior High Schools In Ghana. European Journal of Education Studies.

Torres, K., \& Giddie, L. (2019, July). Educational Technology Professional Development Opportunities in South African Schools. In Global Learn (pp. 248-252). Association for the Advancement of Computing in Education (AACE).

Ugwu, C. N. (2017). Environmental Determinants of Maladaptive Behaviours among Adolescents in Senior Secondary Schools in Nsukka Education Zone of Enugu State (Doctoral dissertation).

Van Durme, K., Goossens, L., Bosmans, G., \& Braet, C. (2018). The role of attachment and maladaptive emotion regulation strategies in the development of bulimic symptoms in adolescents. Journal of abnormal child psychology, 46(4), 881-893.

Yubero, S., \& Navarro, R. (2006). Students' and teachers' views of gender-related aspects of aggression. School Psychology International, 27(4), 488-512. 